\title{
Chemotherapy of pancreatic cancer in patients with poor performance
}

\author{
Dominik Schulz ${ }^{1}$, Hana Algül ${ }^{2}$ \\ ${ }^{1}$ II. Medizinische Klinik, Technische Universität München, München, Germany; ${ }^{2}$ Comprehensive Cancer Center München-TUM, Technische \\ Universität München, München, Germany \\ Correspondence to: Hana Algül, MD, MPH. Comprehensive Cancer Center München-TUM, Technische Universität München, Ismaningerstr. 22, \\ 81675 München, Germany. Email: Hana.Alguel@mri.tum.de. \\ Provenance: This is an invited article commissioned by the Academic Editor Yuhui Fan (Technische Universität München, Germany). \\ Comment on: Macarulla T, Pazo-Cid R, Guillén-Ponce C, et al. Phase I/II trial to evaluate the efficacy and safety of nanoparticle albumin-bound \\ paclitaxel in combination with gemcitabine in patients with pancreatic cancer and an ECOG performance status of 2. J Clin Oncol 2019;37:230-8.
}

Submitted Jul 18, 2019. Accepted for publication Aug 02, 2019.

doi: $10.21037 /$ cco.2019.08.01

View this article at: http://dx.doi.org/10.21037/cco.2019.08.01

Pancreatic cancer is the seventh most leading cause of all cancer related deaths, accounting for $4.5 \%$ of these $(1,2)$. Less than $20 \%$ of the patients who are diagnosed with pancreatic ductal adenocarcinoma present with a nonmetastatic localized disease and surgery is a potential curative option (3). Another third of the patients present with locally advanced nonmetastatic cancer and may undergo neoadjuvant chemotherapy with or without radiation followed by exploration and resection as a possible curative treatment. In most of the cases however, patients are diagnosed with a metastatic disease and chemotherapy is the only viable option to increase overall survival and improve quality of life by relieving symptoms.

First line chemotherapy in a metastatic pancreatic cancer is well defined for patients with good performance score. The ACCORD trial showed superior outcomes for patients in first line FOLFIRINOX versus gemcitabine (overall survival 11.1 vs. 6.8 months, $\mathrm{P}<0.001$ ) (4). The cohort consisted of a total of 342 patients of which $37.4 \%$ patients had ECOG $0,61.9 \%$ were ECOG 1 and $0.6 \%$ had ECOG 2 status. In 2013 the results of the MPACT trial established gemcitabine in combination with nab-paclitaxel $(\mathrm{Gem} / \mathrm{NabPac})$ as a first line therapy in pancreatic cancer (overall survival 8.5 compared 6.7 months with gemcitabine only, $\mathrm{P}<0.001)(5)$. The MPACT trial excluded patients with ECOG equal or higher than 2. To date, there is no head-to-head prospective randomized comparison between first line FOLFIRINOX versus Gem/NabPac. However retrospective meta-analysis shows little to no difference in overall survival between both regimens (6). Meta-analysis also shows that in treatment with $\mathrm{Gem} / \mathrm{NabPac}$ versus FOLFIRINOX there is less grade 3-4 toxicity like nausea with an odd ratio (OR) of 0.11 (95\% CI: $0.03-0.34)$, less neutropenia with OR of 0.71 (95\% CI: $0.54-0.92)$ and less febrile neutropenia [OR 0.45 (95\% CI: 0.29-0.7)] (6). In contrast there was less grade 3-4 neurotoxicity in FOLFIRINOX with an OR of 2.8 (95\% CI: 1.4-5.7) and less anemia (6).

While first line recommendation for good performing patients is well defined, literature on the management of elderly and poor performing patients is sparse. It is generally estimated that only $20 \%$ of patients are eligible for clinical trials because of inability to meet inclusion criteria or due to poor performance status (7). As performance score is known to be a prognostic factor in pancreatic cancer (8), recruitment for the major trials exclude these patients to rule out this potential co-founder. The study presented by Macarulla et al. provides important information to this unresolved issue (9). In their phase I/II trial, the authors evaluate a combination of $\mathrm{Gem} / \mathrm{NabPac}$ in pancreatic cancer patients with ECOG 2. In phase I, there are four study arms with six patients per arm. In arm A, a biweekly schedule of NAB-paclitaxel $\left(150 \mathrm{mg} / \mathrm{m}^{2}\right)$ plus gemcitabine $\left(1,000 \mathrm{mg} / \mathrm{m}^{2}\right)$ was administered. Arm C contained also of biweekly schedule of gemcitabine $\left(1,000 \mathrm{mg} / \mathrm{m}^{2}\right)$ with a standard dose NAB-paclitaxel $\left(125 \mathrm{mg} / \mathrm{m}^{2}\right)$. In 
Arm D, the authors administered a standard schedule of 3 weeks on and 1 week off of NAB-paclitaxel $\left(125 \mathrm{mg} / \mathrm{m}^{2}\right)$ plus gemcitabine $\left(1,000 \mathrm{mg} / \mathrm{m}^{2}\right)$. Arm B consisted also of a standard schedule gemcitabine $\left(1,000 \mathrm{mg} / \mathrm{m}^{2}\right)$ and a reduced dose of NAB-paclitaxel $\left(100 \mathrm{mg} / \mathrm{m}^{2}\right)$. The authors choose $\operatorname{arm} \mathrm{B}$ and $\mathrm{D}$ for their phase II randomizing a total of 221 ECOG 2 patients. Median age was 69 and the proportion of patients older than 75 years was $27.6 \%$. The most frequent grade 3 or 4 toxicities in arms B versus D were anemia (12\% vs. $7 \%$ ), neutropenia ( $32 \%$ vs. $30 \%$ ), thrombocytopenia (7\% vs. $11 \%)$, asthenia (14\% vs.16\%), and neurotoxicity ( $11 \%$ vs. $16 \%)$. There was no statistically significant difference in progression free survival rates between both arms (Arm B: 5.7 months, Arm D: 6.7 months, $\mathrm{P}=0.283$ ). Macarulla et al. conclude that $\mathrm{Gem} / \mathrm{NabPac}$ administered at either 100 or $125 \mathrm{mg} / \mathrm{m}^{2}$ on a standard schedule of 3 weeks on and 1 week off is well tolerated and results in acceptable safety and efficacy in patients with ECOG 2.

While in clinical practice FOLFIRINOX is still first choice in younger patients with good performance status, this study demonstrates that Gem/NabPac can be used safely in patients with poor performance $(\mathrm{ECOG}>1)$. Thus, this study provides relevant and urgently needed evidence for these underrepresented patients who are usually excluded from phase III trials in this field. And yet more trials are needed to improve outcomes while maintaining quality of life even in these patients.

\section{Acknowledgments}

None.

\section{Footnote}

Conflicts of Interest: The authors have no conflicts of interest to declare.

Ethical Statement: The authors are accountable for all aspects of the work in ensuring that questions related to the accuracy or integrity of any part of the work are appropriately investigated and resolved.

\section{References}

1. Bray F, Ferlay J, Soerjomataram I, et al. Global cancer statistics 2018: GLOBOCAN estimates of incidence and mortality worldwide for 36 cancers in 185 countries. CA Cancer J Clin 2018;68:394-424.

2. Global cancer observatory: cancer today. Lyon, France: International Agency for Research on Cancer. Available online: https://gco.iarc.fr/today

3. Sheahan AV, Biankin AV, Parish CR, et al. Targeted therapies in the management of locally advanced and metastatic pancreatic cancer: a systematic review. Oncotarget 2018;9:21613-27.

4. Conroy T, Desseigne F, Ychou M, et al. FOLFIRINOX versus Gemcitabine for Metastatic Pancreatic Cancer. N Engl J Med 2011;364:1817-25.

5. Von Hoff DD, Ervin T, Arena FP, et al. Increased Survival in Pancreatic Cancer with nab-Paclitaxel plus Gemcitabine. N Engl J Med 2013;369:1691-703.

6. Pusceddu S, Ghidini M, Torchio M, et al. Comparative Effectiveness of Gemcitabine plus Nab-Paclitaxel and FOLFIRINOX in the First-Line Setting of Metastatic Pancreatic Cancer: A Systematic Review and Meta-Analysis. Cancers (Basel) 2019. doi: 10.3390/ cancers 11040484.

7. Hoos WA, James PM, Rahib L, et al. Pancreatic cancer clinical trials and accrual in the United States. J Clin Oncol 2013;31:3432-8.

8. Tas F, Sen F, Odabas H, et al. Performance status of patients is the major prognostic factor at all stages of pancreatic cancer. Int J Clin Oncol 2013;18:839-46.

9. Macarulla T, Pazo-Cid R, Guillen-Ponce C, et al. Phase I/II Trial to Evaluate the Efficacy and Safety of Nanoparticle Albumin-Bound Paclitaxel in Combination With Gemcitabine in Patients With Pancreatic Cancer and an ECOG Performance Status of 2.J Clin Oncol 2019;37:230-8.
Cite this article as: Schulz D, Algül H. Chemotherapy of pancreatic cancer in patients with poor performance. Chin Clin Oncol 2019;8(Suppl 1):S22. doi: 10.21037/cco.2019.08.01 